\title{
Colonic findings in Churg-Strauss syndrome
}

A 66-year-old woman presented with nausea, loss of appetite, fever, and abdominal pain. She had livedo reticularis on the anterior surfaces of both legs ( $\bullet$ Fig. 1). Her medical history included asthma, drug allergy, and sinusitis. Laboratory tests revealed marked eosinophilia $\left(14.8 \times 10^{9} / \mathrm{L}\right)$, anemia (hemoglobin $10.9 \mathrm{~g} / \mathrm{dL}$ ), inflammation (C-reactive protein [CRP] $7.4 \mathrm{mg} / \mathrm{dL}$ ), high levels of rheumatoid factor $(3561 \mathrm{IU} / \mathrm{mL}$ ) and serum IgE $(1130 \mathrm{IU} / \mathrm{mL})$, but normal myeloperoxidase (MPO)-antineutrophil cytoplasmic antibody (ANCA) and proteinase 3 (PR3)ANCA. Examination of the stool did not reveal any parasites.

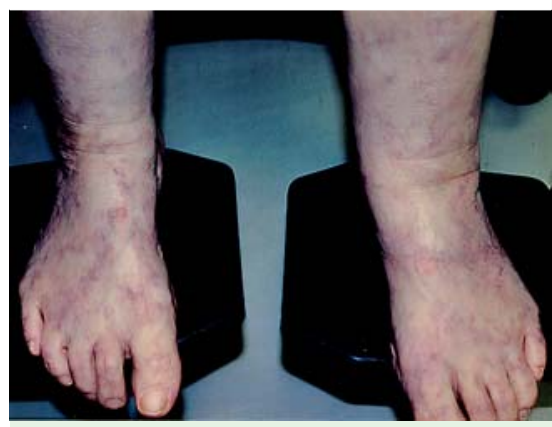

Fig. 1 Photograph of the anterior aspect of the legs showing livedo reticularis in a 66-yearold woman with a history of asthma and drug allergy who presented with nausea, loss of appetite, fever, and abdominal pain.
We performed computed tomography (CT) and esophagogastroduodenoscopy (EGD) to investigate the abdominal pain, but neither test detected any abnormality. Colonoscopy showed multiple discrete ulcers in the terminal ileum ( $\bullet$ Fig. 2 a) and colon ( Fig. $\mathbf{2}$ b, c). In addition, electromyography revealed mononeuritis multiplex.

Biopsies were taken from the area of skin showing livedo reticularis. These revealed vasculitis ( Fig.3a), with features including the destruction of an artery, fibrin thrombus formation, and an eosinophilic infiltrate consistent with the diagnosis of Churg-Strauss Syndrome (CSS) [1]. No obvious vasculitis was observed in the biopsy specimen from the colon, but exfoliation of the mucous cell layer was detected, which indicated ischemia caused by the vasculitis ( Fig. 3 b).

CSS is a rare diffuse vasculitis with a prevalence of 2.4-6.8 per 1 million people per year [2]. Involvement of the cardiovascular, central nervous, and renal systems is associated with a poor prognosis. Intestinal perforation is also typically fatal and can be difficult to predict, often occurring after prednisolone therapy has been started. To reduce the risk of intestinal perforation, cyclophosphamide has also been used and has been reported as being effective [3].
In this case the patient was administered prednisolone only, which resulted in a rapid improvement in both her symptoms and laboratory data. A follow-up colonoscopy revealed complete resolution of the ulcers ( Fig.4). This case highlights that it is important to examine the gastrointestinal tract in people with CSS and abdominal pain.

Endoscopy_UCTN_Code_CCL_1AD_2AF

\section{Competing interests: None}

\section{T. Yoshioka ${ }^{1,2}$, T. Kusaka ${ }^{2}$, H. Seno ${ }^{1,2}$}

${ }^{1}$ Division of Gastroenterology, Kyoto-Katsura Hospital, Kyoto, Japan

2 Department of Gastroenterology and Hepatology, Kyoto University Graduate School of Medicine, Kyoto, Japan

\section{References}

1 Masi AT, Hunder GG, Lie JT et al. The American College of Rheumatology 1990 criteria for the classification of Churg-Strauss syndrome (allergic granulomatosis and angiitis). Arthritis Rheum 1990; 33: 1094-1100

2 Noth I, Strek ME, Leff AR. Churg-Strauss syndrome. Lancet 2003; 361: 587-594

3 Nakamura Y, Sakurai Y, Matsubara T et al. Multiple perforated ulcers of the small intestine associated with allergic granulomatous angiitis: report of a case. Surg Today 2002; $32: 541-546$
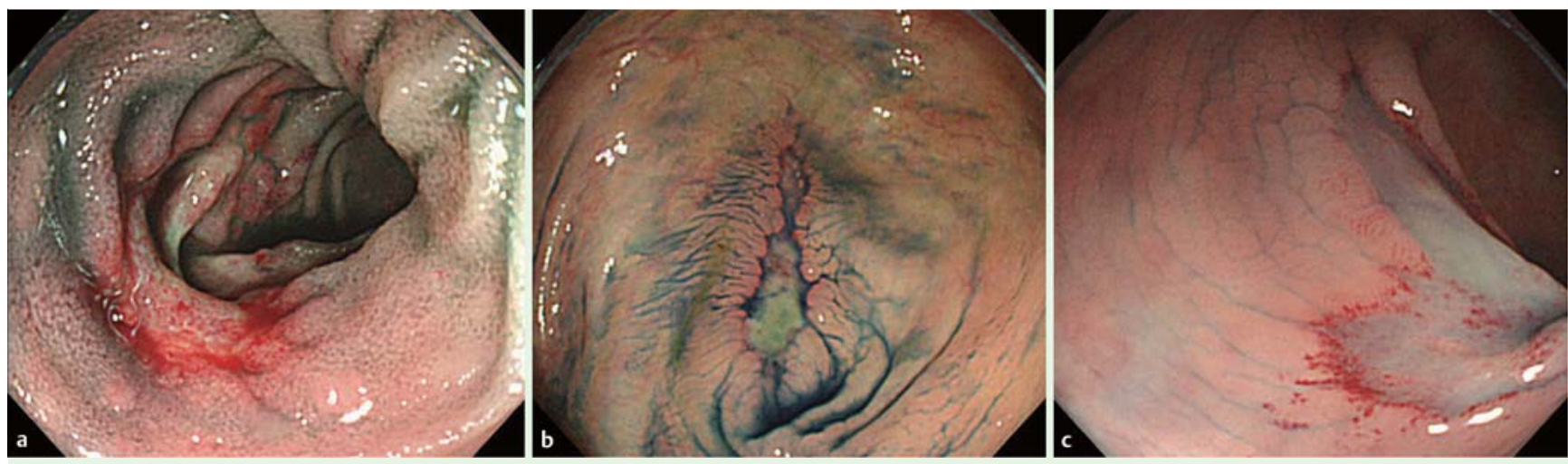

Fig. 2 Endoscopic views of discrete ulcers in: a the terminal ileum; $\mathbf{b}, \mathbf{c}$ the colon. 


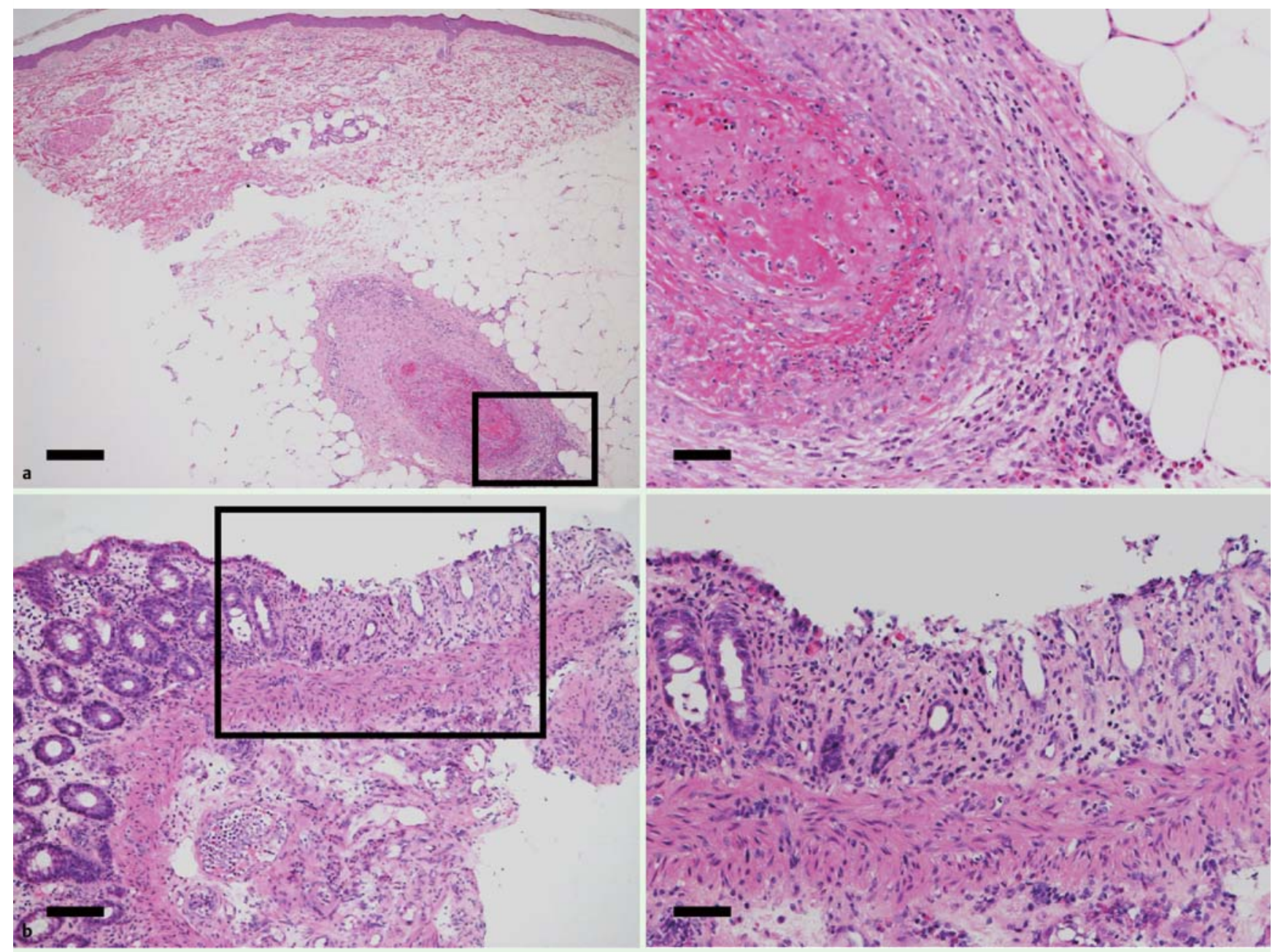

Fig. 3 Histological appearances (right-hand images are higher power views of the marked fields) of the biopsy specimens from: a the area of livedo reticularis showing vasculitis (the bars represent $200 \mu \mathrm{m}$ in the left-hand image and $50 \mu \mathrm{m}$ in the right-hand image); $\mathbf{b}$ a colonic ulcer showing exfoliation of the mucous cell layer (the bars represent $100 \mu \mathrm{m}$ in the left-hand image and $50 \mu \mathrm{m}$ in the right-hand image).
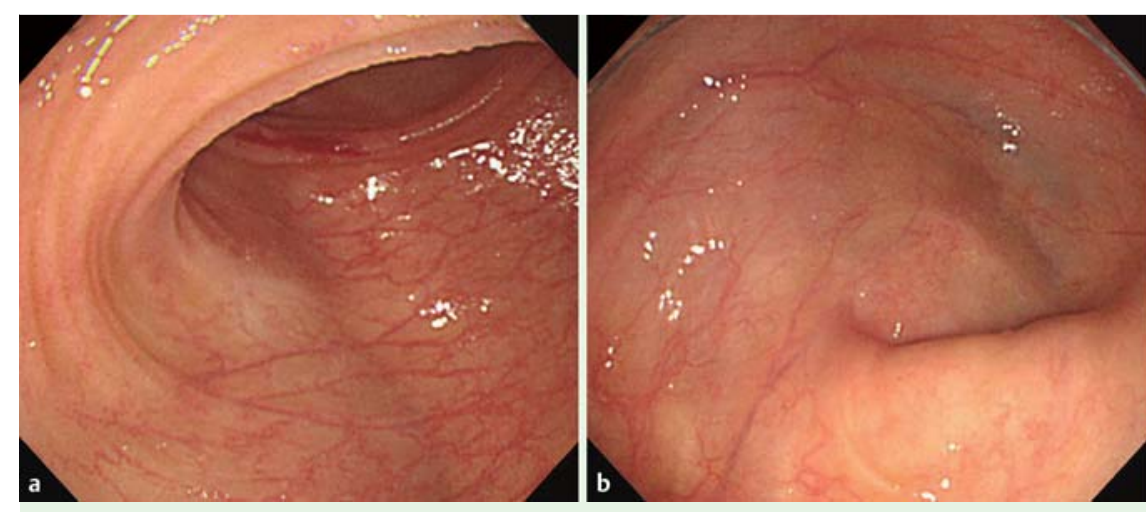

Fig. 4 Endoscopic views after the patient had been treated with prednisolone showing resolution of the ulcers in: $\mathbf{a}$ the terminal ileum; $\mathbf{b}$ the colon.
Bibliography

DoI http://dx.doi.org/

10.1055/s-0033-1344062

Endoscopy 2013; 45: E185-E186

(c) Georg Thieme Verlag KG

Stuttgart · New York

ISSN 0013-726X

\section{Corresponding author \\ T. Yoshioka, MD}

Department of Gastroenterology and Hepatology Kyoto University Graduate School of Medicine

54 Shogoin-Kawahara-cho

Sakyo-ku

Kyoto 606-8507

Japan

Fax: +81-75-7514303

takuto@kuhp.kyoto-u.ac.jp 